\title{
APRENDIZAJES PARA LA INCLUSIÓN DESDE LAS ENSEÑANZAS DE PAULO FREIRE
}

Learning for inclusion from the teachings of Paulo Freire

Aprendizagem para a inclusão dos ensinamentos de Paulo Freire

\section{Miguel González González}

Universidad de León. Correo electrónico: migog@unileon.es

\begin{abstract}
Resumen
En un contexto actual de crisis económica y social en España, los postulados pedagógicos de Paulo Freire no han perdido vigencia. A través de un trabajo de campo etnográfico con el aula de Antropología Social del Grado en Educación Social-Ule y revisando fuentes bibliográficas que incluyen su obra planteamos que la Universidad tiene que ocuparse no solamente de la cultura de la docencia, sino también de la "cultura del silencio", dejando de un lado el rol pasivo del docente. Los resultados muestran que aunque el riesgo de exclusión social sigue creciendo en España, a través del método transformador de Freire es posible reducir las desigualdades a través de la educación.

Palabras clave: Freire; enseñanza activa; inclusión educativa; exclusión social
\end{abstract}

\begin{abstract}
In the context of current economic and social crisis in Spain, the pedagogical principles of Paulo Freire have not lost validity. Through ethnographic fieldwork with the students of Social Anthropology of the degree in Social Education-Ule and checking bibliographic sources that include his work, we suggest that the University has to deal with not only the culture of teaching, but also of the "culture of silence", leaving aside the passive role of the teacher. The results show that although the risk of social exclusion continues to grow in Spain, through the transformer method of Freire it is possible to reduce inequalities through education.
\end{abstract}

Keywords: Freire; active teaching; inclusive education; social exclusion 


\section{Resumo}

No contexto da crise económica e social em Espanha, os princípios pedagógicos de Paulo Freire não perderam validade. Através do trabalho de campo etnográfico com elaula de Antropologia Social do curso de Educação Social-Ule e verificação de fontes bibliográficas que incluem seu trabalho, sugerimos que a Universidade tem que enfrentar não só a cultura do ensino, mas também da "cultura do silêncio", deixando de lado o papel passivo do professor. Os resultados mostram que, embora o risco de exclusão social continua a crescer em Espanha, através do transformador método de Freire é possível reduzir as desigualdades através da educação.

Palavras-chave: Freire; ensino ativo; educação inclusiva; exclusão social

\section{Introducción: De la educación tradicional a las enseñanzas activas}

Para muchos autores, en algunos centros de formación de docentes todavía se sigue reproduciendo la cultura escolar tradicional en la que se refuerza el rol pasivo del docente y no se facilita el aprendizaje de los estudiantes Robalino (2005), Messina (1999). En este sentido, Murillo (2006) ya señalaba que los expertos y las instituciones académicas reclamaban la necesidad de dar un salto cualitativo en la formación de pedagogos. Según Morales (2016) no se trata de hacer grandes innovaciones, sino que muchas innovaciones menores pueden ser muy rentables para el aprendizaje de los alumnos. Para Robalino (2005) la enseñanza basada en metodologías activas está centrada en el estudiante, en su capacitación y competencias, por lo que el aprendizaje es un proceso constructivo y no receptivo; como entiende Glaser (1991), el conocimiento se estructura en redes y la nueva información se va acoplando a las ya existentes.

Freire (2006) ya planteaba en 1966 en su libro "La pedagogía de la Autonomía" que "enseñar no es transferir conocimientos, sino crear las posibilidades para su propia producción o construcción", resaltando el respeto a la autonomía del ser educando. De la misma manera, en otro libro de 1968, "La pedagogía del oprimido", Freire (2005a) critica la concepción "bancaria" de la educación consistente en que el único margen de acción que se ofrece a los educandos es el de recibir depósitos, guardarlos y archivarlos, lo que ocurre cuando en vez de comunicarse, el educador hace comunicados. En otra de 
sus obras, "Educación y cambio" Freire (1976) se refiere al hombre inacabado que se sabe inacabado y por eso se educa. Afirma que el hombre debe ser el sujeto de su propia educación, no debe ser el objeto de ella, porque nadie educa a nadie, de forma que el hombre puede auto-reflexionar sobre sí mismo, y ahí está la raíz de la educación. Como señala Freire (2005b) en su teoría de acción dialógica, el diálogo es una reivindicación a favor de la opción democrática de los educadores, no pretende ser un método de enseñanza sino de aprendizaje.

\section{Objetivo y metodología}

El objetivo de este trabajo es analizar la vigencia de los postulados pedagógicos de Freire en el contexto de crisis económica y social acercándonos a su aplicación en el momento actual como forma de evitar la exclusión social y educativa. Para lograrlo, se realiza un trabajo de campo etnográfico con los estudiantes de Antropología Social del segundo curso del Grado en Educación Social-ULE, del año 2016, además de un análisis documental y de fuentes que incluye la obra de Paulo Freire, con el criterio de que los futuros educadores sociales dispongan de recursos en su práctica profesional, especialmente en su trabajo con colectivos en riesgo de exclusión. En este estudio, se toma principalmente como estudio de caso, a los inmigrantes de habla no hispana, en la línea que marcó la UNESCO (2015) en la Declaración de Incheon, hacia una educación inclusiva. En este tipo de aprendizaje los estudiantes trabajan en equipo, discutiendo, argumentando y evaluando lo que aprenden, focalizándose principalmente en los aspectos culturales de la educación, y poniendo especial atención en la identidad étnica y la diversidad cultural a través de la realización de sus propios trabajos de campo.

\section{Resultados y discusión}

A la vista del trabajo realizado, los estudiantes de Educación Social han tomado conciencia de la importancia de la educación como un camino para disminuir la exclusión social en un contexto de crisis económica, que según el INE afecta en España al 28,6\% de los ciudadanos, y entre ellos principalmente a los extranjeros con estudios básicos y sin empleo. Los alumnos reconocen la diversidad cultural y la importancia de respetar la identidad étnica de los inmigrantes educandos, por lo que deben utilizar la empatía como un recurso principal. En esta línea Solla (2013) indica que en el ámbito de la educación formal, la inclusión supone una adaptación del sistema a los alumnos y no al contrario. La "educación problematizadora" apunta hacia la liberación y la 
independencia, y hoy en día ha logrado sus mayores éxitos en la construcción de aprendizajes significativos en la alfabetización de inmigrantes adultos. Como apunta Echeita (2006), cambiar el estado de las cosas nos compete como ciudadanos y como educadores. Para Freire la alfabetización no es una simple adquisición de la habilidad mecánica de la lectura y la escritura, sino un proceso crítico y dialéctico entre la lectura del contexto y la lectura del texto (Freire, 1998). En esta línea, en su trabajo etnográfico, los alumnos comprenden que la lengua es mucho más que un modo de comunicarse, que es la "sangre" por la que se transmite una cultura y por tanto hay que protegerla. En este sentido, siguiendo con Freire (1974) la pedagogía acepta la sugerencia de la antropología: se impone pensar y vivir "la educación como práctica de la libertad", ya que "el hombre es un ser de relaciones y no solo de contactos, no solo está en el mundo sino con el mundo".

\section{Conclusiones}

En un contexto de crisis educativa y social en España y en el mundo, donde las diferencias sociales son cada vez más grandes y donde la Encuesta de condiciones de vida refleja que las personas en riesgo de exclusión social en España aumentan cada día, los postulados de Freire adquieren mayor valor y a la vista del trabajo realizado y sobre todo en cuanto a la formación de educadores se refiere podemos afirmar que la obra de Freire sigue vigente hoy en día. La educación y la necesidad de aprender influyen directamente en el bienestar y la calidad de vida de las personas y como tal pueden ayudar a las personas a salir de la exclusión. Como él defendía, el hombre debe ser protagonista de su propia historia mediante la acción. La Universidad debe ocuparse por lo tanto de la "cultura del silencio" para dar voz a los que se excluyeron y a los que callaron.

\section{Referencias}

Echeita, G. (2006). Educación para la inclusión. Educación sin exclusiones. Madrid: Morata.

Freire, P. (1974). La educación como práctica de la libertad. (15ª ed). Buenos Aires: Siglo Veintiuno Editores.

Freire, P. (1976). Educación y cambio. Buenos Aires: Ediciones Búsqueda.

Freire P. (1998). El proceso educativo según Paulo Freire y Enrique Pichón-Rivière. México: Plaza y Valdes Editores. 
Freire, P. (2005 a). Pedagogía del oprimido. Buenos Aires: Siglo XXI. [1968]

Freire, P. (2005 b). Educación y mudanza. México: Editorial La Mano. [1966]

Freire, P. (2006). Pedagogía de la autonomía: saberes necesarios para la práctica educativa. Buenos Aires: Siglo XXI.

Glaser R. (1991). The Maturing of the relationship between the science of learning and cognition and educational practice. Learning and Instruction, 1, 129-144.

Messina, G. (1999). Investigación en o investigación acerca de la formación docente: un estado del arte en los noventa. Revista Iberoamericana de Educación, $N^{\circ} 19$.

Morales, P. (2016). Investigación e innovación educativa. REICE. Revista Iberoamericana sobre Calidad, Eficacia y Cambio en Educación, 8(2).

Murillo, F. J. (2006). Modelos innovadores en la formación inicial docente. Santiago de Chile: Unesco.

Robalino, M. (2005). ¿Actor o protagonista? Dilemas y responsabilidades sociales de la profesión docente. Revista PRELAC, $N^{\circ}$ 1. UNESCO/OREALC. Pág. 13

Solla, C. (2013). Guía de Buenas Prácticas en Educación Inclusiva. Madrid. Save the Children. 